\title{
Adolesan bir hastada travma görmüş dişlerin multidisipliner yaklaşım ile rehabilitasyonu: Vaka raporu
}

\author{
Elif Yaşa ${ }^{1}$, Bilal Yaşa ${ }^{2}$, Duygu Yıldızeli ${ }^{1}$, Cüneyt Asım Aral ${ }^{3}$
}

Selcuk Dent J, 2016; 3: 27-33

Basvuru Tarihi: 22 Ağustos 2015 Yayına Kabul Tarihi: 11 Şubat 2016

\begin{abstract}
Esthetic rehabilitation of traumatized teeth with adolescent: A case report

In adolescents suffered from dental trauma, most appropriate treatment option should be preferred due to psychological effects of tooth loss in the anterior region. Pulpal perforation width and localization of fracture line play an important role in determining treatment options. Function and aesthetics should be re-established, and remaining tooth structure and surrounding tissues should be protected mechanically and biologically and with the help of restorative treatment. This case report describes multidisciplinary esthetic treatment approach of adolescent patient who has complicated crown fractures located subgingivally in anterior region. 15-year-old female patient referred to our clinic after a day trauma. Sectional complicated crown fractures located subgingivally on the right and left centrals, an horizontal crown fracture including pulp on the left lateral and non-complicated crown fracture on the left canine were determined in intraoral examination. After flep operation was performed to eliminate subgingival fracture line and isolation of root canal, fracture line was restored with composite restoration. Following endodontic treatments of both centrals and left lateral, glass fiber posts were inserted into the centrals. Restorations of left lateral and canine were finished incrementally by using nanofill composite resin. After the periodontal healing, central teeth was restored with CAD/CAM nano-ceramic resin crown restorations and cemented using dual-cure resin cement. After the treatment, marginal adaptation and gingival compatibility of the restorations were very good. The final result was satisfactory for both the clinician and the patient. An integration of CAD/CAM systems thanks to advantages and material diversity with clinician's treatment planning of the adolescents suffered from dental trauma increases clinical success.
\end{abstract}

\section{KEYWORDS}

CAD-CAM, dental crown, tooth factures

Dişlerde kırılma ya da yer değiştirmeye neden olan ve dişeti, periodontal ligament ya da kemik gibi destek dokularda hasarla sonuçlanan dental travmalar, diş hekimliğinde önemli bir yere sahiptir (Feliciano ve ark. 2006). Dental travmalar genellikle öz

Adolesan bir hastada travma görmüş dişlerin multidisipliner yaklaşım ile rehabilitasyonu: Vaka raporu

Dental travma geçiren genç hastalarda özellikle ön bölgedeki diş dokusu kaybının psikolojik etkileri nedeniyle en uygun tedavi seçeneği tercih edilmelidir. Pulpanın tamamen açıldığı durumlarda perfore olan pulpanın genişliği ve kırık hattının lokalizasyonu tedavi seçeneğinin belirlenmesinde önemli rol oynamaktadır. Uygulanacak olan restoratif tedaviyle de fonksiyon ve estetik yeniden sağlanmalı, kalan diş yapısı ve dişi çevreleyen dokular hem biyolojik hem de mekanik açıdan korunmalıdır. Bu vaka raporunda, anterior dişlerinde dişeti altına uzanan komplike kron kırıkları bulunan adolesan bir hastanın multidisipliner estetik rehabilitasyonu anlatımaktadır. 15 yaşındaki bayan hasta geçirdiği travmadan bir gün sonra kliniğimize başvurdu. Yapılan intraoral muayenede, üst sağ ve sol santral dişlerde dişeti altına uzanan komplike kron kırığı, üst sol lateral dişte pulpayı içine alan horizontal kron kırığı ve üst sol kanin dişte ise komplike olmayan kron kırığı tespit edildi. Kök kanalının izolasyonu ve kırık hattının dişeti seviyesine çıkarılabilmesi için periodontal flep kaldırıdıktan sonra kıık hattı kompozit ile restore edildi. Santral dişler ve sol lateralin kanal tedavileri tamamlanarak santral dişlerin kök kanalına fiber-post yerleştirildi. Sol lateral ve kanin dişler nanofil içerikli kompozit rezin ile restore edildi. Periodontal iyileşmenin ardından santral dişlere nano-seramik CAD/CAM rezin kron restorasyonlar yapıldı ve dual-cure rezin siman kullanılarak simante edildi. Tedavi sonrasında restorasyonların marjinal adaptasyon ve gingival uyumlarının çok iyi olduğu gözlendi. Tedavi sonucu hem hasta hem de hekim için memnuniyet vericiydi. Klinisyenlerin dental travma geçirmiş adolesan bireylerin tedavi planlanmalarına sağladığı avantajlar ve sunduğu materyal zenginliği ile CAD/CAM sistemleri entegre etmesi klinik başarıyı artıracaktır.

\section{ANAHTAR KELIMELER}

CAD/CAM, dental kron, diş kırıkları de düşme, trafik kazası ve spor yaralanması sonucunda karşımıza çıkmaktadır. Travmadan en çok etkilenen dişler ise dişlerin protrüziv konumlanması nedeniyle maksiller keser dişlerdir (Reis ve ark. 2004).

\footnotetext{
${ }^{1}$ Şifa Üniversitesi Diş Hekimliği Fakültesi Restoratif Diş Tedavisi Anabilim Dalı, İzmir

2 İzmir Katip Çelebi Üniversitesi Diş Hekimliği Fakültesi Restoratif Diş Tedavisi Anabilim Dalı, İzmir

${ }^{3}$ Şifa Üniversitesi Diş Hekimliği Fakültesi Periodontoloji Anabilim Dalı, İzmir
} 
Travma sonrası dental dokularda ortaya çıkan biyolojik, fonksiyonel ve estetik kayıpların hızlı ve doğru bir biçimde tedavi edilmesi gerekmektedir. Travmaya uğramış dişlerin tedavisinde başarı ve prognozu etkileyen en önemli parametreler arasında erken tanı, doğru teşhis ve uygun materyal kullanımı yer almaktadır. Travmaya maruz kalmış dental dokuların rehabilitasyonu için birbirinden farklı tedavi seçenekleri mevcuttur. Diş dokusundaki madde kaybı miktarına, kırık hattının lokalizasyonuna, pulpa dokusunun canlılığına, dişin estetik bölgede yer almasına ve hastanın estetik beklentisine göre tedavi seçenekleri değişebilmektedir (Olsburgh ve ark. 2002). Dental travmalarda, kronu ilgilendiren kırıklar, komplike ve komplike olmayan kırıklar olmak üzere ikiye ayrılmaktadır (Olsburgh ve ark. 2002, Asgary ve Fazlyab 2014, Bajaj ve ark. 2015). En sık görüleni ise mine, dentin ve pulpayı ilgilendiren komplike kron kırığıdır (Kocak ve ark. 2008).

Tedavi alternatiflerinin belirlenmesinde en önemli faktör, travmanın pulpa dokusuna verdiği zararın miktarıdır. Kırık hattının dişeti altına ulaşmadığı durumlarda endodontik tedavi sonrası direkt kompozit restorasyonlar uygulanabilirken, diş eti altına uzanan kırıklarda ise endodontik tedavinin ardından post uygulamalarıyla restorasyon desteklenmektedir (Vitale ve ark. 2004). Post uygulamasından sonra dişte meydana gelen madde kaybı direkt restorasyon yapılmasına izin vermeyecek büyüklükte ise kron restorasyonları tercih edilmektedir (Tsurumachi ve ark. 2012, Ulusoy ve ark. 2012).
Geçmişte fazla kayıplı dişlerin restorasyonu için döküm ve metal postlar kullanılırken, günümüzde adeziv diş hekimliğindeki gelişmelerle birlikte estetik özellikleri geliştirilmiş, diş dokusuna bağlanabilen ve elastiklik modülü dentine daha yakın olan fiber postlar kullanılmaya başlanmıştır (Möllersten ve ark. 2002, Zorba ve Özcan 2007). Fiber postların rezin simanlar ve kompozit kor materyalleriyle birlikte kullanımı da restorasyona bir bütünlük kazandırmaktadır.

Postla retansiyon kazandırılmış dişler kalan koroner dokunun miktarına göre direkt veya indirekt yöntemlerle restore edilebilmektedir (Fasbinder ve ark. 2002). Estetiğin ön planda olduğu ve yeterli dayanıklıığın sağlanamadığı durumlarda ise daha çok indirekt restorasyonlar tercih edilmektedir (Fasbinder ve ark. 2002, Denry ve Kelly 2008). Günümüzde dijital teknolojinin diş hekimliğindeki yansımaları CAD/CAM sistemlerin kullanımının ve indirekt restorasyonların uygulanabilirliğinin artmasına neden olmuştur (Moörmann 2006, Strub ve ark. 2006). Bilgisayar destekli tasarım ve üretim sağlayabilen CAD/CAM ile dijital ortamda tasarlanan restorasyon, seramik ya da kompozit blokların yerleştirildiği bilgisayar destekli freze sistemiyle üretilmektedir (Allen ve ark. 2003, Strub ve ark. 2006). Aynı zamanda CAD/CAM ile tek seansta ve estetik sonuçlar elde edilmesi iyi bir tedavi alternatifinin doğmasına neden olmuştur (Santos Jr ve ark. 2013). Bu vaka raporunda travma sonrası üst anterior dişlerde parçalı komplike kron kırıkları bulunan hastanın CAD/CAM destekli estetik rehabilitasyonu anlatılmaktadır.
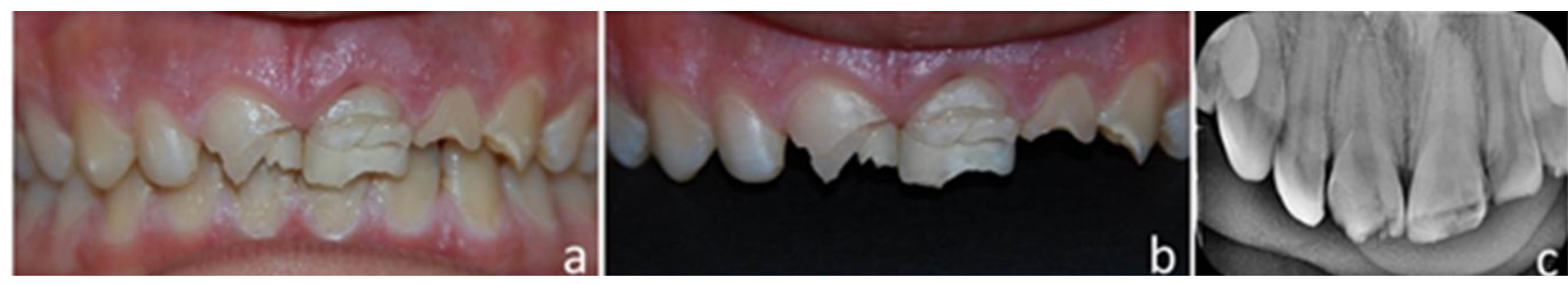

Resim 1.

a,b ) Travma sonrası dişlerin klinik görüntüsü

c ) Dişlerin başlangıç radyografisi

\section{OLGU SUNUMU}

15 yaşında bayan hasta Şifa Üniversitesi Diş Hekimliği Fakültesi Restoratif Diş Tedavisi bölümüne geçirdiği travmadan bir gün sonra üst anterior dişlerinde yer alan parçalı komplike kron kırıkları nedeniyle başvurdu. Yapılan intraoral muayene sonucunda, santral dişlerde dişeti altına uzanan komplike kron kırıkları, sol lateral dişte pulpayı içine alan horizontal kron kırığı ve sol kanin dişte ise komplike olmayan kron kırığı tespit edildi. Radyolojik muayenede ise kökte ya da alveoler kemikte kırık olmadığı görüldü (Resim 1). Kırık hattının ortaya çıkarılarak subgingival bölgenin restorasyonu ve kök kanalının izolasyonu için periodontal cerrahi yapılması planlandı. Lokal anestezi altında santral dişlerin palatinal bölgesinden 15c nolu bistüri ile tam kalınlıklı mukoperiostal flep kaldırılarak, kırık parçalar uzaklaştırıldı ve dişeti altına uzanan kırık hattı ortaya çıkarıldı. Otomatris sistemi (Adapt SuperCap Matrix, Kerr, ABD) yardımıla kan ve nem kontaminasyonu engellendikten sonra subgingival bölge iki aşamalı self-etch adeziv (Clearfil SE Bond, Kuraray, Japonya) ve nanofil içerikli kompozit rezin (Filtek Ultimate, 3M 
ESPE, ABD) kullanılarak restore edildi (Resim 2). Aynı seansta santral dişlerin ve sol lateral dişin de kanal ekstirpasyonu yapılarak belirlenen çalışma boyunda step-back yöntemiyle genişletildi. Seanslar arası kök kanalları kalsiyum hidroksit tozu (Kalsin, Aktu Tic, Türkiye) distile su ile karıştırılarak kapatıldı. Tedaviden 15 gün sonra kanal dolgusu epoksi rezin içerikli kanal patı $\mathrm{AH}$ plus (Dentsply Maillefer, İsviçre) ve guta perka (Dentsply Maillefer, İsviçre) kullanılarak lateral kompaksiyon yöntemiyle tamamlandı. Santral dişlerin kanal dolumunun ardından fiber post (Unicore, Ultradent, ABD) apikalde $>4 \mathrm{~mm}$ guta olacak şekilde yerleştirilerek self adeziv siman (Rely X U200, 3M ESPE, ABD) ile simante edildi ve LED (Valo, Ultradent, ABD) ışık cihazı kullanılarak her yönden 40 sn. polimerize edildi. Post üst yapısı kompozit rezinle tamamlanarak dişler preparasyona hazır duruma getirildi. Sol lateral ve kanin dişlerin direkt restorasyonu için üç aşamalı total-etch adeziv sistem (Optibond FL, Kerr, ABD) uygulandı ve nanofil içerikli kompozit rezinin (Filtek Ultimate, 3M ESPE, ABD) A2 dentin ve A2 mine tonları seçilerek tabakalama yöntemiyle bitirildi. Restorasyonların polisaj işlemleri bitirme diskleri (Sof-Lex, 3M Espe, ABD) ve elmas partiküllü polisaj patı (Diomand Polish, Ultradent, ABD) kullanılarak yapıldı (Resim 3). Periodontal iyileşmenin ardından santral dişlere hastanın yaşı da göz önünde bulundurularak CAD/CAM sistemi ile hazırlanan nano-seramik rezin kron restorasyon yapımına karar verildi. Dișler chamfer frez kullanılarak prepare edildi. Intraoral tarayıcı (Cerec Omnicam, Sirona, Almanya) yardımıyla dijital ölçüleri alınan dişlere A2 HT renk tonunda nano-seramik rezin kronlar (Lava Ultimate; 3M ESPE, ABD) yapıldı (Resim 4). Restorasyonların bireysel karakteristikleri eksiltme tekniği ile sağlandı ve dual-cure rezin siman (Variolink N, Ivoclar Vivadent, Liechstentein) kullanılarak simante edildi (Resim 5). Tedavi sonrasında restorasyonların marjinal adaptasyonlarının ve gingival uyumlarının çok iyi ve tedavi sonucunun hem hasta hem de hekim için memnuniyet verici olduğu tespit edildi.
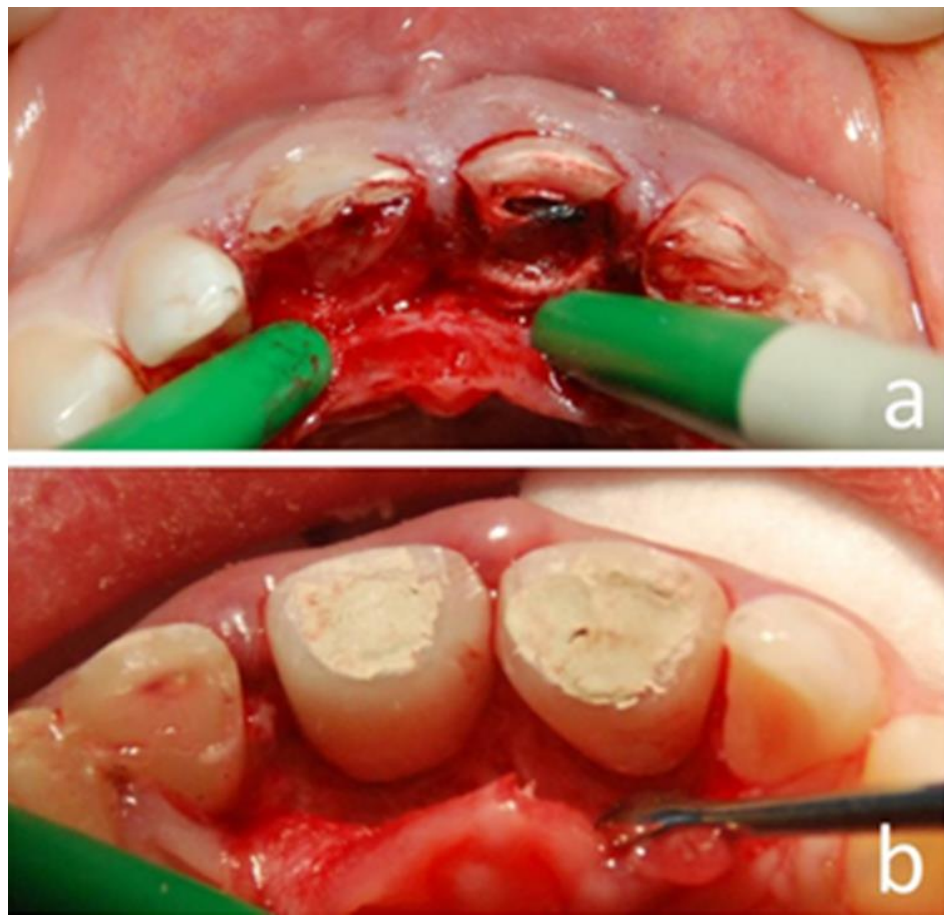

Resim 2

a ) Kırık hattının ortaya çıkarılması

b ) Kırık hattının kompozit ile restorasyonu
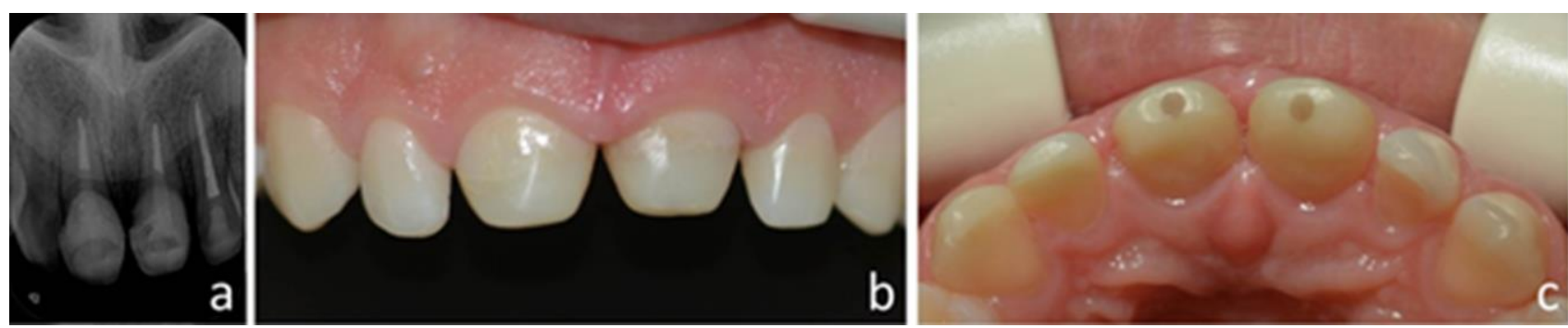

Resim 3.

a ) Kanal tedavisi tamamlanmış ve post yerleştirilmiş dişlerin radyografisi

b ) Restorasyonların vestibül görüntüsü

c ) Restorasyonların oklüzal görüntüsü 

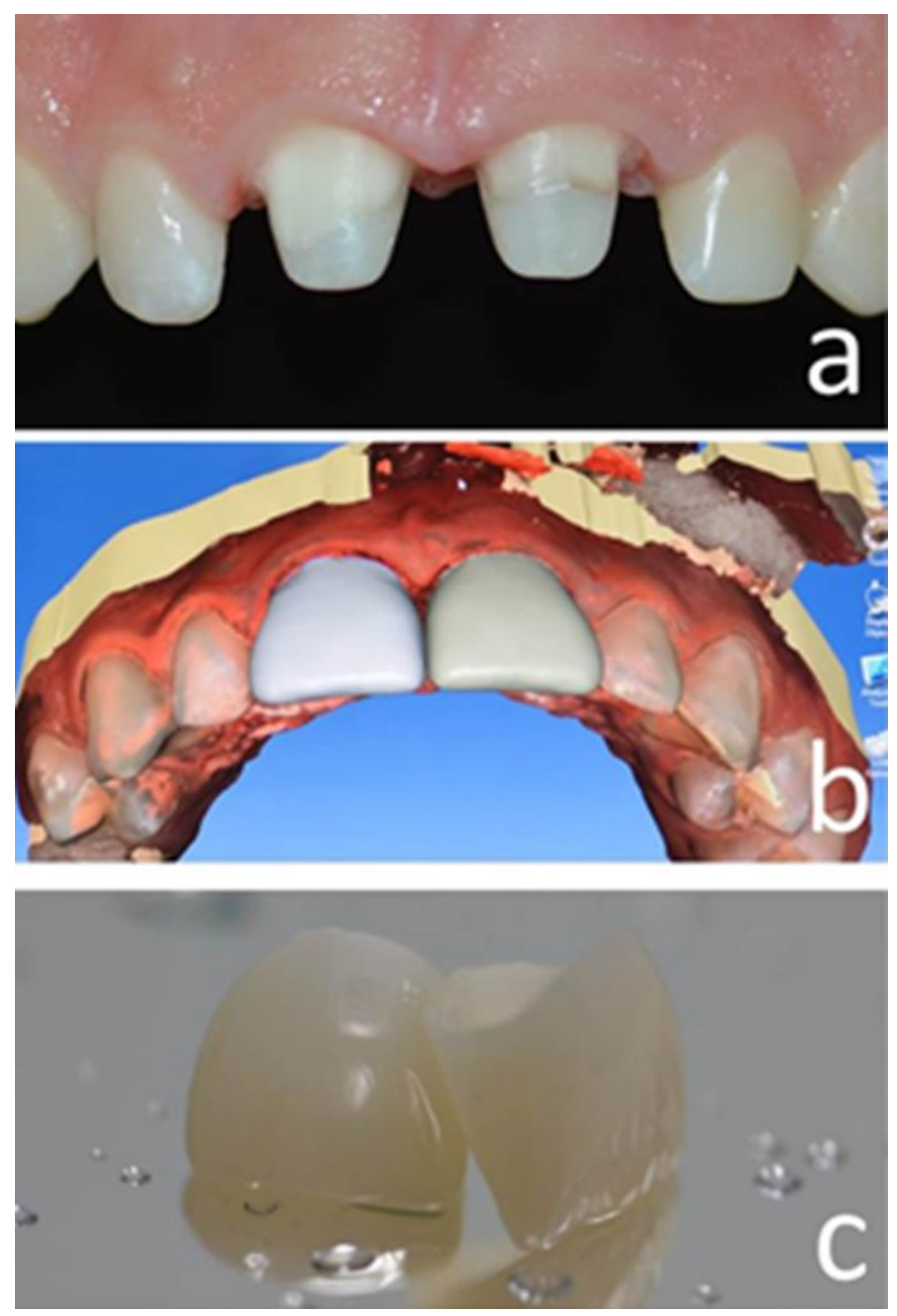

Resim 4.

a ) Dişlerin preparasyonu

b ) Restorasyonların CAD/CAM ile tasarımı

c ) $\mathrm{CAD} / \mathrm{CAM}$ ile üretilmiş nano-seramik rezin kron restorasyonlar

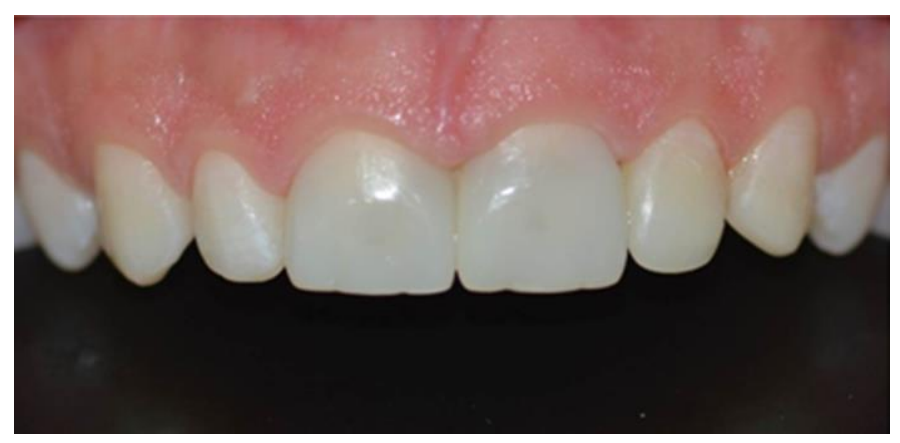

Resim 5.

Tedavi sonrası dişlerin klinik görünümü

\section{TARTIŞMA}

Dental yaralanmalardan sonra dişlerin, yumuşak dokuların korunması ve dentisyonun devamlılığının sağlanması diş hekimliğinde önemli bir yere sahiptir (Sgan-Cohen ve ark. 2005). Travma olgularında kırık hattının lokalizasyonu ve kalan diş dokusunun miktarı hem dişin prognozunu hem de tedavi prosedürünü etkilemektedir (Welbury ve ark. 2002). Özellikle komplike kron kırığı vakalarının estetik, biyolojik ve fonksiyonel açıdan değerlendirilmesi ve tedavisinde multidisipliner yaklaşımda bulunulması gerekmektedir (Ulusoy ve ark. 2012).

Dental travmalarda, kırık hattının subgingivalde yer alması dişin prognozu etkilemektedir (Tsurumachi ve ark. 2012). Bu tür vakalarda restorasyonun ideal şartlarda yapılabilmesi için kırık hattı supragingival seviyeye çıkartılmalıdır (Olsburgh ve ark. 2002, Bajaj ve ark. 2015). Bu da gingivektomi, flep operasyonu veya kron boyu uzatma gibi periodontal cerrahi yaklaşımlarıyla gerçekleşmektedir (Krastl ve ark. 2010). Subgingival seviyedeki kırık hattının supragingival seviyeye taşınmasında kompozit rezinlerin kullanımı, yumuşak dokular ile uyumunun kabul edilebilir olması ve diş dokusuna kuvvetli bağlanması nedeniyle tercih sebebidir (Welbury ve ark. 2002, Jagannath-Torvi ve Kala 2014).

Geçmişte travma görmüş dişlerin tedavisinde metal postlar, monokromatik kompozit restorasyonlar, metal destekli seramik kronlar kullanılırken, adeziv diş hekimliğindeki gelişmelerle birlikte materyal seçenekleri de değişmeye başlamıştır. Örneğin, biyolojik uyumları ve fiziksel özellikleri iyi olan ancak ışı̆̆ geçirmeyen ve korozyon sonucu dişetinde renklenmeye neden olan metal postların yerini cam fiber postlar almaya başlamıştır (Cheung 2005, Peroz ve ark. 2005, Zhang ve ark. 2012). Cam fiber postların elastiklik modülünün dentine yakın olması vertikal kök kırığı riskini azaltırken, beraberinde kullanılan rezin simanla adeziv bağlanarak monoblok bir yapı oluşturması da üst restorasyonun dayanıklıı̆ını artırmaktadır (Freedman 2001).

Madde kaybı fazla olmayan direkt restorasyonla tedavi edilebilecek travma olgularında kompozit rezinlerin kullanımı ise en iyi seçenektir (Öz ve ark. 2006, Badami ve Reddy 2011). Özellikle genç bireylerde kompozitlerin kullanımı, sağlam diş dokusu kaldırmadan kayıp dokunun geriye kazandırımasında çok konservatif bir yaklaşımdır. Son yıllarda geliştirilen kompozitlerin tabakalama tekniği ile kullanımı da dişe ait tüm karakteristik özelliklerin oluşturulmasını sağlamaktadır. 
Geçmişten günümüze kullanılan metal destekli seramik restorasyonların optik özelliklerinin memnun edici olmaması ve hastaların estetik beklentilerinin yüksek olması materyal çeşitliliğini artırmıştır (Santos Jr ve ark. 2013). Özellikle son yıllarda dijital teknolojinin hızla gelişmesi de diş hekimliğinde kullanılan sistem ve materyallere başka bir boyut kazandırmıştır. Bunun bir ürünü olan CAD/CAM sistemler restorasyonun tasarlanabilmesini ve laboratuar ortamına girmeden restorasyonun üretilmesine olanak vermektedir (Mörmann 2004, Lin ve ark. 2010). Ayrica bilgisayar teknolojisi sayesinde teknisyene bağlı oluşan hatalar ortadan kaldırılarak yüksek hassasiyette restorasyonların oluşturulması sağlanmaktadır (Fasbinder ve ark. 2005, Moörmann 2006).

CAD/CAM ile kullanılmak üzere piyasada esas olarak iki çeşit materyal bulunmaktadır. Bunlar, cam seramikler ve hibrit materyallerdir (Strub ve ark. 2006, Chen ve ark. 2014). Cam seramiklerin estetik özelliklerinin mükemmelliği ve renklenmeye karşı dayanıklılığı, düşük aşınma direnci göstermesi rezin kompozitlere oranla daha çok tercih edilmelerine neden olmuştur. Ancak tek seansta üretilebilen CAD/CAM seramik restorasyonların ek bir laboratuar aşaması olan glazür işlemi gerektirmesi, kırıldığında tamir edilmesinin güç olması ve karşıt dişte istenmeyen aşınmalara neden olması gibi dezavantajlarının bulunması yeni materyallerin geliştirilmesini sağlamıştır (Awada ve Nathanson 2015). Bu nedenle son yillarda rezin ve seramik materyallerin fiziksel ve estetik özelliklerini bir arada bulunduran hibrit seramik materyaller geliştirilmiştir (Nemli ve Güngör 2015). Bu materyallerin kırıldığında ağız içerisinde tamirlerinin kolay olması, polisajlarının hemen yapılabilmesi ve karşıt dentisyonda aşınmaya neden olmaması özellikle diş gelişim aşamasında olan genç bireylerde de tercih edilmesini sağlamıştır (Awada ve Nathanson 2015). Bundan dolayı bu vaka raporunda hastanın yaşı göz önünde bulundurularak kron restorasyonları nano-seramik rezin materyaller ile gerçekleştirilmiştir.

\section{SONUÇ}

Travma görmüş dişlerde meydana gelen harabiyetin miktarı tedavinin kompleks bir hal almasına neden olmaktadır. Özellikle aşıı madde kaybı bulunan vakalarda zamanında ve multidisipliner yaklaşımda bulunmak tedavinin başarı bir şekilde sonuçlanmasını sağlamaktadır. Aynı zamanda vakaya uygun materyal seçimi de tedavinin başarısını etkilemektedir. Kalan kök yapısını sağlamlaştırmak, krondaki madde kaybını telafi etmek ve hastanın estetik görünümünü sağlamak için post-kor uygulamalarının ardından CAD/CAM restorasyonların tercih edilmesi hastanın tedavi sürecini kısaltmaktadır. Klinisyenlerin dental travma geçirmiş adolesan bireylerin tedavi planlanmalarına sağladığı avantajlar ve sunduğu materyal zenginliği ile CAD/CAM sistemleri entegre etmesi klinik başarıyı artıracaktır. 


\section{KAYNAKLAR}

Allen K, Schenkel A, Estafan D, 2003. An overview of the Cerec 3D CAD/CAM system. Gen Dent, 3, 234235.

Asgary S, Fazlyab M, 2014. Management of complicated crown fracture with miniature pulpotomy: A case report. Iran Endod J, 3, 233.

Awada A, Nathanson D, 2015. Mechanical properties of resin-ceramic CAD/CAM restorative materials. J Prosthet Dent, doi:10.1016/j.prosdent.2015.04.016.

Badami V, Reddy SK, 2011. Treatment of complicated crown-root fracture in a single visit by means of rebonding. J Am Dent Assoc, 6, 646-650.

Bajaj P, Chordiya R, Rudagi K, Patil N, 2015. Multidisciplinary approach to the management of complicated crown-root fracture: A case report. J Int Oral Health, 4, 88-91.

Chen C, Trindade FZ, de Jager N, Kleverlaan CJ, Feilzer AJ, 2014. The fracture resistance of a CAD/CAM Resin Nano Ceramic (RNC) and a CAD ceramic at different thicknesses. Dent Mater, 9, 954962.

Cheung W, 2005. A review of the management of endodontically treated teeth: Post, core and the final restoration. J Am Dent Assoc, 5, 611-619.

Denry I, Kelly JR, 2008. State of the art of zirconia for dental applications. Dent Mater, 3, 299-307.

Fasbinder DJ, 2002. Restorative material options for CAD/CAM restorations. Compend Contin Educ Dent, 10, 911-916.

Fasbinder DJ, Dennison JB, Heys DR, Lampe K, 2005. The clinical performance of CAD/CAM generated composite inlays. J Am Dent Assoc, 12, 1714-1723.

Feliciano KMPdC, Caldas AdF, 2006. A systematic review of the diagnostic classifications of traumatic dental injuries. Dent Traumatol, 2, 71-76.

Freedman GA, 2001. Esthetic post-and-core treatment. Dent Clin North Am, 1, 103-116.

Jagannath-Torvi S, Kala M, 2014. Restore the natural-A review and case series report on reattachment. J Clin Exp Dent, 5, e595.

Kocak S, Cinar S, Kocak M, Kayaoglu G, 2008. Intraradicular splinting with endodontic instrument of horizontal root fracture-case report. Dent Traumatol, $5,578-580$.
Krastl G, Filippi A, Zitzmann NU, Walter C, Weiger R, 2010. Current aspects of restoring traumatically fractured teeth. Eur J Esthet Dent, 2, 124-141.

Lin $\mathrm{CL}$, Chang $\mathrm{YH}$, Chang $\mathrm{CY}$, Pai CA, Huang SF, 2010. Finite element and Weibull analysis to estimate failure risks in the ceramic endocrown and classical crown for endodontically treated maxillary premolar. Eur J Oral Sci, 1, 87-93.

Moörmann WH, 2006. The evolution of the Cerec system. J Am Dent Assoc, 137 Suppl, 7S-13S.

Möllersten L, Lockowandt $P$, Lindén L-A, 2002. A comparison of strengths of five core and post-andcore systems. Quintessence Int, 2, 140-149.

Mörmann WH, 2004. The origin of the Cerec method: A personal review of the first 5 years. Int $\mathrm{J}$ Comput Dent, 1, 11.

Nemli SK, GüngörMB, 2015. Endodontik tedavili dişin CAD/CAM rezin-nano seramik endokron ile tek seansta restorasyonu. Turkiye Klinikleri J Dental Sci Cases, 2, 94-100.

Olsburgh S, Jacoby T, Krejci I, 2002. Crown fractures in the permanent dentition: Pulpal and restorative considerations. Dent Traumatol, 3, 103-115.

Öz IA, Haytaç MC, Toroğlu MS, 2006. Multidisciplinary approach to the rehabilitation of a crown-root fracture with original fragment for immediate esthetics: A case report with 4-year follow-up. Dent Traumatol, 1, 48-52.

Peroz I, Blankenstein F, Lange KP, Naumann M, 2005. Restoring endodontically treated teeth with posts and cores: A review. Quintessence Int, 9, 737-746.

Reis A, Loguercio A, Kraul A, Matson E, 2004. Reattachment of fractured teeth: a review of literature regarding techniques and materials. Oper Dent, 2, 226-233.

Santos Jr GC, Santos Jr M, Rizkalla AS, Madani D, El-Mowafy O, 2013. Overview of Cerec CAD/CAM chairside system. Gen Dent, 1, 36-40.

Sgan-Cohen HD, Megnagi G, Jacobi Y, 2005. Dental trauma and its association with anatomic, behavioral, and social variables among fifth and sixth grade schoolchildren in Jerusalem. Community Dent Oral Epidemiol, 3, 174-180.

Strub JR, Rekow ED, Witkowski S, 2006. Computeraided design and fabrication of dental restorations: Current systems and future possibilities. J Am Dent Assoc, 9, 1289-1296. 
Tsurumachi T, Matsumoto S, Kobayashi Y, Ohara K, Suzuki Y, et al. 2012. Esthetic and endodontic management of a deep crown-root fracture of a maxillary central incisor. J Oral Sci, 4, 359-362.

Ulusoy AT, Tunc ES, Cil F, İsci D, Lutfioglu M, 2012. Multidisciplinary treatment of a subgingivally fractured tooth with indirect composite restoration: A case report. J Dent Child, 2, 79-83.

Vitale MC, Caprioglio C, Martignone A, Marchesi U, Botticelli A, 2004. Combined technique with polyethylene fibers and composite resins in restoration of traumatized anterior teeth. Dent Traumatol, 3, 172-177.

Welbury R, Kinirons M, Day P, Humphreys K, Gregg $T$ 2002. Outcomes for root-fractured permanent incisors: a retrospective study. Pediatr Dent, 2, 98102.

Zhang Y, Yu W, Jiang X, Qiu J, Sun S, et al. 2012. The microtensile bond strengths of four resin core materials and fiber posts and their micromorphologic characteristics. Quintessence Int, 4, e39-47.

Zorba YO, Özcan E, 2007. Reattachment of coronal fragment using fiber-reinforced post:A case report. Eur J Dent, 3, 174.

Yazışma Adresi:

Elif YAŞA

Şifa Üniversitesi

Diş Hekimliği Fakültesi Restoratif Diş Tedavisi A.D.

35100, Bayraklı, İzmir, Türkiye

Tel : +902323080000

Faks : +90 2324864147

E-mail: dt.eliffiliz@hotmail.com 